\title{
EFEITOS DA CALAGEM NA FERTILIDADE DO SOLO E NA NUTRIÇÃo E PRODUTIVIDADE DA GOIABEIRA ${ }^{(1)}$
}

\author{
William Natale ${ }^{(2)}$, Renato de Mello Prado ${ }^{(3)}$, Danilo Eduardo \\ Rozane $^{(4)}$ \& Liliane Maria Romualdo ${ }^{(4)}$
}

\begin{abstract}
RESUMO
A acidez do solo é um dos mais importantes fatores que limitam a produção em regiões tropicais. Assim, o objetivo deste trabalho foi avaliar os efeitos da calagem na fertilidade do solo e na nutrição e produtividade da goiabeira (Psidium guajava L.). O experimento foi realizado na Estação Experimental de Citricultura de Bebedouro, São Paulo, em um Latossolo Vermelho distrófico ( $V=26 \%$ na camada de 0-20 cm), no período de agosto/1999 a julho/2006. As doses de calcário empregadas foram: 0; 1,85; 3,71; 5,56 e 7,41 $\mathrm{t}$ ha $^{-1}$. Durante 78 meses após aplicação do corretivo foram realizadas análises químicas de solo. Foi feita avaliação do estado nutricional e da produtividade durante cinco safras agrícolas. A calagem promoveu alteração nos atributos químicos do solo ligados à acidez, elevando o pH, Ca, Mg, soma de bases (SB) e saturação por bases (V) e diminuindo $\mathrm{H}+\mathrm{Al}$, até $60 \mathrm{~cm}$. Os teores foliares de Ca e Mg aumentaram com as doses de calcário. As maiores produções acumuladas de frutos estiveram associadas a um valor de $\mathrm{V}$ de $50 \%$ na linha e $65 \%$ na entrelinha das goiabeiras.
\end{abstract}

Termos de indexação: Psidium guajava, acidez do solo, calcário, nutrição mineral.

\section{SUMMARY: EFFECTS OF LIMING ONSOIL FERTILITY, PLANTNUTRITION AND GUAVA YIELD}

Soil acidity is one of the most important constraints to agricultural production in the tropics. For this reason, the objective of this research was to evaluate the effects of soil liming on the performance of guava (Psidium guajava L.) trees. The experiment took place

\footnotetext{
(1) Recebido para publicação em março de 2007 e aprovado em julho de 2007.

(2) Professor Adjunto do Departamento de Solos e Adubos, Universidade Estadual Paulista - FCAV/UNESP. Rod. Paulo Donato Castellane s/n, CEP 14884-900 Jaboticabal (SP). Bolsista do CNPq. E-mail: natale@fcav.unesp.br

(3) Professor do Departamento de Solos e Adubos, FCAV/UNESP. Bolsista do CNPq. E-mail: rmprado @fcav.unesp.br

(4) Pós-Graduando, FCAV/UNESP. E-mails: danilorozane@yahoo.com.br; lilianeromualdo@yahoo.com.br
} 
at the Citrus Experimental Station in Bebedouro, state of São Paulo, Brazil. The soil was a Typic Haplustox ( $V=26 \%$ in the 0 to $20 \mathrm{~cm}$ layer) between August 1999 and July 2006. The following doses of limestone were employed: $0,1.85$, 3.71, 5.56, and $7.41 t \mathrm{ha}^{-1}$. During the 78 months after starting the experiment, soil chemical attributes were periodically examined. Over a period of five years, the guava tree leaves were analyzed for micro-and macronutrients and the fruit yield was determined. Liming improved the evaluated soil chemical attributes: $\mathrm{pH}$, calcium (Ca), magnesium $(\mathrm{Mg}), \mathrm{BS}, \mathrm{V}$, and hydrogen and aluminum $(H+A l)$ down to a depth of $60 \mathrm{~cm}$ of samples taken from both in and between tree rows. The Ca and Mg levels increased in the leaves also. The highest fruit yields were observed when soil base saturation reached $50 \%$ in the rows and $65 \%$ between rows.

Index terms: Psidium guajava L., soil acidity, lime, mineral nutrition.

\section{INTRODUÇÃO}

A goiaba é a mais brasileira das frutas tropicais, apesar de não haver consenso entre os pesquisadores sobre a localização exata de seu centro de origem na América Tropical. É apreciada pelo seu aroma e sabor característicos, além do alto valor alimentício, sendo uma das frutas mais consumidas no Brasil.

A expansão dos pomares de goiabeira tem ocorrido em todo o País, seja pela sua adaptabilidade a várias condições edafoclimáticas, seja pela dupla aptidão dos frutos, que podem ser consumidos in natura ou industrializados, agregando valor na fabricação de vários produtos.

Segundo Rey (1987), a reputação de rusticidade implica que normalmente sejam reservadas as áreas marginais das regiões para o plantio de goiabeiras. Apesar disso, informações da literatura indicam alta resposta dessa frutífera à melhoria da fertilidade do solo (Natale, 1993, 1999). Isso se deve, de um lado, à pobreza generalizada dos solos tropicais em nutrientes e à elevada acidez e, de outro, ao melhoramento genético da goiabeira, com o desenvolvimento de plantas mais produtivas, porém mais exigentes em termos nutricionais.

Dentre os fatores ambientais do solo, os ligados à acidez (pH, saturação por bases, acidez potencial e disponibilidade de nutrientes) são os que mais interferem na produtividade, especialmente nas regiões tropicais (Sanchez \& Salinas, 1983).

A aplicação de corretivos em culturas anuais, com incorporação homogênea ao solo, é técnica conhecida e tem sido usada pelos agricultores normalmente, ainda que sem a regularidade devida. Entretanto, em culturas perenes, a incorporação de corretivos é mais complexa, devido às características intrínsecas dessas culturas e à falta de informações técnicas (Quaggio, 1986), como acontece, normalmente, na maioria dos pomares do Estado de São Paulo.

As plantas frutíferas, assim como todas as perenes, permanecem longos períodos explorando praticamente o mesmo volume de solo, razão pela qual o ambiente radicular, em especial com respeito à acidez, merece a máxima atenção. Apesar da indiscutível importância para a maioria das culturas (Quaggio, 1986), são escassas as informações sobre a prática da calagem na fase de implantação dos pomares de goiabeiras. Há consenso, porém, de que essa é a principal maneira de melhoria do ambiente radicular para as mudas que vão se desenvolver e de que seu pleno estabelecimento tem relação direta com as condições iniciais de fertilidade do solo.

Em condições de acidez, a calagem promove a neutralização do $\mathrm{Al}^{3+}$, a elevação do $\mathrm{pH}$ e o fornecimento de $\mathrm{Ca}$ e $\mathrm{Mg}$, possibilitando a proliferação de raízes, com reflexos positivos no crescimento da parte aérea das plantas. Contudo, devido à baixa solubilidade e à lenta movimentação do calcário ao longo do perfil do solo, há obrigatoriedade de se fazer distribuição uniforme e incorporação profunda, antecedendo a implantação do pomar (Quaggio, 2000). Isso permite maior contato entre o corretivo e as fontes de acidez, resultando num efeito adequado da prática da calagem, o que deve garantir o eficiente aproveitamento de água e de nutrientes contidos nessas camadas (Demattê \& Vitti, 1992).

Do ponto de vista financeiro, alguns insumos agrícolas fazem parte do custo de produção, como fertilizantes, herbicidas e defensivos. Outros, como o calcário, devem ser considerados um investimento, visto que os benefícios da calagem perduram além de um ano, ou de uma safra agrícola. Isso se deve ao efeito residual dos corretivos de acidez do solo, sendo o tempo de duração desse efeito dependente de vários fatores (Quaggio, 2000), entre os quais: condições edafoclimáticas, cultura, manejo da área e tipo de corretivo empregado. Com relação ao calcário, podese afirmar que, quanto maior a granulometria (até o limite da peneira ABNT n.10 - partículas menores que $2 \mathrm{~mm}$ ), maior seu efeito residual, valendo também o inverso. Isso porque a ação do calcário depende do contato com o solo. Assim, quanto menor a partícula (para um mesmo calcário), maior o contato, mais rápida sua ação e, portanto, a correção da acidez; contudo, o efeito residual será menor (Barber, 1967). Outra variável do efeito residual do calcário é o manejo 
do solo. As práticas agrícolas convencionais, que mobilizam anualmente o solo, favorecem as reações de correção da acidez, diminuindo porém o efeito residual. Em situações em que isso não ocorre, como no caso dos pomares de plantas perenes, como as frutíferas utilizadas neste experimento, há total dependência da aplicação inicial do corretivo, no momento de implantação da cultura, visto que incorporações após instalação do pomar podem trazer graves prejuízos ao crescimento e desenvolvimento das plantas, devido aos danos - especialmente ao sistema radicular. Entretanto, estabelecer qual o efeito residual do calcário aplicado na instalação de um pomar de goiabeiras, ou seja, por quanto tempo durarão os benefícios da calagem inicial, é assunto muito pouco estudado. As principais razões são a necessidade de experimentação de longa duração, de gastos com mãode-obra e condução dos ensaios e de resultados que necessitam de consolidação para publicação. Esses são, pois, apenas alguns dos aspectos que justificam a quase ausência de experimentação dessa natureza. Entretanto, em situações de elevada acidez é imperativa a realização da calagem, e informações concernentes ao efeito residual são vitais para o bom manejo das culturas de alto rendimento, para utilização do insumo mais adequado e para realização do investimento financeiro com segurança.

Além disso, o uso constante de fertilizantes que acidificam o solo, sobretudo os nitrogenados, pode agravar o problema, considerando que em pomares de frutíferas com alta produção as doses de adubos normalmente são elevadas. Desse modo, conhecer fatores limitantes à produção de goiabas permite a adoção de programas de calagem e adubação com resultados favoráveis ao aumento da produtividade e, conseqüentemente, do lucro do fruticultor.

Tendo em vista o exposto, fica evidente a importância da correção da acidez do solo e a carência de pesquisas sobre o assunto. Assim, o presente trabalho buscou acompanhar os efeitos da calagem na implantação de um pomar de goiabeiras e seus reflexos na fertilidade do solo, na nutrição e produtividade das plantas, bem como avaliar a duração do efeito residual da aplicação inicial do corretivo.

\section{MATERIAL E MÉTODOS}

O experimento foi realizado na Estação Experimental de Citricultura de Bebedouro, no município de Bebedouro-SP, num Latossolo Vermelho distrófico típico (Embrapa, 1999). As análises químicas do solo foram realizadas em maio/1999, antes da aplicação dos tratamentos (Quadro 1).

Foi utilizado o delineamento experimental em blocos casualizados, com cinco tratamentos e quatro repetições. Os tratamentos foram constituídos de doses crescentes de calcário dolomítico, com PRNT = $100 \%$. As doses foram calculadas considerando-se os resultados médios da análise química das camadas de 0-20 e 20-40 cm (Quadro 1) e, também, ajustandose as doses para incorporação do calcário na camada de $0-30 \mathrm{~cm}$ de profundidade. Tomou-se como referência a dose calculada para atingir a saturação por bases $(\mathrm{V})$ igual a $70 \%\left(3,71 \mathrm{t} \mathrm{ha}^{-1}\right)$, recomendada para a goiabeira no Estado de São Paulo (Santos \& Quaggio, 1996) e, a partir desta, como segue: $\mathrm{D}_{0}=$ zero; $\mathrm{D}_{1}=$ metade da dose; $\mathrm{D}_{2}=$ dose total; $\mathrm{D}_{3}=1,5$ vez a dose; $\mathrm{e}_{4}=$ duas vezes a dose necessária para elevar $\mathrm{V}$ a $70 \%$, correspondendo a: $0 ; 1,85 ; 3,71 ; 5,56$; e 7,41 t ha-1.

O calcário foi aplicado ao solo em julho/agosto de 1999 e, após quatro meses, foi implantado o pomar (dezembro/1999), utilizando-se goiabeiras (cv. Paluma) propagadas a partir de estacas herbáceas.

O calcário foi aplicado manualmente em toda a superfície do terreno, metade antes da incorporação com arado de aivecas e a outra metade aplicada e incorporada com grade aradora, ambos os implementos abrangendo a camada de $0-30 \mathrm{~cm}$.

A adubação básica na cova de plantio constou da mistura de $180 \mathrm{~g}$ de $\mathrm{P}_{2} \mathrm{O}_{5}$ na forma de superfosfato simples granulado, $20 \mathrm{~L}$ de composto orgânico curtido à base de esterco de bovino, além de $1 \mathrm{~g}$ de $\mathrm{B}$ e $2 \mathrm{~g}$ de $\mathrm{Zn}$, na forma de ácido bórico e de sulfato de zinco, respectivamente.

Em dezembro de 1999 realizou-se o plantio das mudas no campo, no espaçamento de $7 \mathrm{~m}$ entre linhas e 4,2 $\mathrm{m}$ entre plantas. As parcelas experimentais

Quadro 1. Análise química do solo, em diferentes profundidades, realizada em maio/1999, antes da instalação do experimento

\begin{tabular}{|c|c|c|c|c|c|c|c|c|c|c|c|}
\hline Camada & $\mathrm{pH} \mathrm{CaCl}_{2}$ & MO & $P$ resina & $\mathbf{K}$ & $\mathrm{Ca}^{2+}$ & $\mathrm{Mg}^{2+}$ & $\mathbf{H}+\mathbf{A l}$ & SB & $\mathbf{T}$ & Al & V \\
\hline $\mathrm{cm}$ & & $\mathrm{g} \mathrm{dm}^{-3}$ & $\mathrm{mg} \mathrm{dm} \mathrm{m}^{-3}$ & 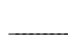 & 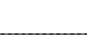 & 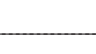 & $\mathrm{Amol}_{\mathrm{c}} \mathrm{dm}^{-3}$ & & & - & $\%$ \\
\hline $0-20$ & 4,7 & 18 & 6 & 1,3 & 9 & 4 & 40 & 14,3 & 54,3 & 8 & 26 \\
\hline $20-40$ & 4,4 & 16 & 3 & 0,8 & 6 & 4 & 41 & 10,8 & 51,8 & 11 & 21 \\
\hline $40-60$ & 4,4 & 16 & 4 & 0,6 & 7 & 4 & 45 & 11,6 & 56,6 & 12 & 20 \\
\hline $60-80$ & 4,0 & 9 & 1 & 0,3 & 7 & 3 & 58 & 10,3 & 68,3 & 11 & 15 \\
\hline
\end{tabular}


foram compostas por cinco plantas, sendo consideradas as três centrais como árvores úteis para as avaliações e por linhas de bordadura de ambos os lados.

Aos sete meses após o plantio das mudas (julho de 2000), instalou-se o sistema de irrigação por microaspersão, colocando-se um microaspersor por planta, com vazão de $26 \mathrm{~L} \mathrm{~h}^{-1}$. O manejo da irrigação seguiu a recomendação de Bernardo (2002) para frutíferas em geral, acionando-se o sistema de irrigação quando era consumido de 25 a $40 \%$ da disponibilidade de água no solo avaliado por tensiometria. As precipitações médias anuais para o período de 1999 a 2006 foram, respectivamente, de $1.236 ; 1.636 ; 1.157$; $1.421 ; 1.384 ; 1.191 ; 1.305$; e $1.579 \mathrm{~mm}$.

A adubação durante todo o período experimental seguiu as indicações de Natale et al. (1996), para a cultura da goiabeira, considerando-se a fertilidade do solo, a idade do pomar, as exigências da cultura e a produtividade esperada de frutos. O parcelamento das doses, bem como a localização de aplicação dos fertilizantes, atenderam às recomendações dos mesmos autores, empregando-se como fontes: uréia, sulfato de amônio, superfosfato triplo, MAP e cloreto de potássio, de forma alternada, durante a condução do experimento (1999 a 2006). Além dos fertilizantes químicos, aplicaram-se anualmente $40 \mathrm{~L}$ de composto curtido (à base de esterco de bovino), em torno da planta, sob a projeção da copa, entre os meses de julho e agosto.

As podas de formação e produção da goiabeira seguiram as indicações de Piza Júnior (1994). Os tratos culturais para controle de plantas daninhas, pragas e doenças foram os normalmente empregados na região, observando recomendações de Piza Júnior \& Kavati (1994).

As amostragens de solo na entrelinha da goiabeira foram realizadas aos $4,8,12,16,22,28,34,40,46$, 52,66 e 78 meses após incorporação do calcário ao solo (1999 a 2006). Na linha de plantio da frutífera, na faixa de adubação, as amostragens de solo foram realizadas aos $12,16,22,28,34,40,46,52,66 \mathrm{e}$ 78 meses após incorporação do corretivo. Foram retiradas 12 subamostras por parcela, em cada camada, para constituir uma amostra composta. Para isso, utilizou-se trado tipo holandês, amostrandose as camadas de 0-20, 20-30, 30-40 e 40-60 cm. As determinações analíticas nas amostras de solo seguiram os métodos descritos por Raij et al. (2001).

O estado nutricional das plantas foi determinado pela amostragem de folhas, conforme Natale et al. (1996) para a goiabeira, que indicam a coleta do terceiro par de folhas recém-maduras (com pecíolo), a partir da extremidade do ramo, à época de pleno florescimento da cultura, em número de quatro pares de folhas por árvore, em toda a volta da planta. Assim, nos meses de setembro/novembro de 2001 a 2005 , realizou-se a diagnose foliar das goiabeiras. As determinações dos teores de macro e micronutrientes no tecido vegetal seguiram métodos descritos por Bataglia et al. (1983).
A produção das três plantas úteis de cada parcela foi avaliada durante cinco anos agrícolas (safras de 2001/02, 2002/03, 2003/04, 2004/05 e 2005/06), no período de dezembro/janeiro a abril/maio de cada ano agrícola. A resposta das goiabeiras à calagem, nas safras de 2001/02 e 2002/03, foi avaliada por Prado (2003).

Os resultados foram submetidos a análises de variância e de regressão. De acordo com PimentelGomes (1985), foram realizadas análises de variância conjunta para os dados de solo, admitindo-se as diferentes épocas de amostragens como variáveis. Para isso, foram selecionadas e consideradas as variáveis cujos quadrados médios residuais não diferiram em mais de sete vezes. A análise estatística foi realizada pelo programa estatístico SAS (1985).

\section{RESULTADOS E DISCUSSÃO}

\section{Efeito dos tratamentos no solo}

A análise conjunta dos valores $\mathrm{pH}$, soma de bases (SB) e saturaçao de bases (V), bem como a concentração de $\mathrm{Ca}$, de $\mathrm{Mg}$ e a $\mathrm{H}+\mathrm{Al}$ das análises químicas do solo não mostrou interação significativa entre as doses de calcário e as épocas de amostragem, em todas as camadas estudadas, tanto na entrelinha como na linha de plantio das goiabeiras. A ausência de interação sugere que as modificações nas propriedades químicas do solo, em função das doses de calcário empregadas, foram proporcionalmente semelhantes nas diferentes épocas de amostragem.

Verificaram-se alterações significativas de $\mathrm{pH}$, $\mathrm{H}+\mathrm{Al}, \mathrm{Ca}^{2+}, \mathrm{Mg}^{2+}, \mathrm{SB}$ e V em todas as camadas de solo analisadas (exceto o $\mathrm{pH}$ na camada de $40-60 \mathrm{~cm}$, tanto na linha como na entrelinha da frutífera) (Figura 1). Podem-se comprovar as modificações ao se comparar à análise inicial da área (Quadro 1).

Com o aumento das doses de corretivo, houve elevação significativa do $\mathrm{pH}, \mathrm{Ca}^{2+}, \mathrm{Mg}^{2+}, \mathrm{SB}$ e V, e redução significativa do $\mathrm{H}+\mathrm{Al}$, tanto na linha como na entrelinha das goiabeiras. Os efeitos da calagem sobre essas variáveis do solo tiveram ajuste linear, independentemente do local de amostragem (entrelinha ou linha) e da camada analisada. Contudo, as alterações foram mais intensas na região em que o calcário foi incorporado $(0-30 \mathrm{~cm})$, o que pode ser constatado pelo coeficiente angular das equações de regressão, que decresce com a profundidade de amostragem do solo (Figuras 1 e 2).

Verifica-se que os atributos químicos ligados à acidez do solo mantiveram-se com valores menores, ao longo do experimento, na entrelinha da cultura, em relação à projeção da copa das goiabeiras. Isso era esperado, visto que o manejo do pomar pressupõe a aplicação localizada de elevadas doses de fertilizante nitrogenado, cuja característica é de acidificação do 
solo durante o processo de nitrificação (Malavolta, 2006). Não se pode desprezar, também, a ação das frutíferas sobre o solo, absorvendo Ca e Mg para sua nutrição e exsudando prótons (Engels \& Marschner, 1995). Vale lembrar, ainda, que o pomar era irrigado, o que de todo modo contribui para maiores modificações na projeção da copa das goiabeiras, devido à estreita relação entre o movimento da água e a lixiviação de nitrato (Libardi \& Reichardt, 1978).

As alterações dos atributos químicos do solo analisadas neste trabalho, abaixo da camada de incorporação do corretivo, podem ser explicadas de muitas formas, apesar de conhecidas a baixa solubilidade e a restrita movimentação do calcário no perfil do solo (Gonzales-Érico et al., 1979).

Salienta-se que existem vários fatores que podem explicar o deslocamento das partículas de calcário ao longo do perfil do solo neste experimento, podendo-se destacar a contribuição de natureza física, como os canais deixados pela decomposição de raízes (Pearson et al., 1962), em função da atividade da macro e microfauna, visto que a área era recém-desbravada à época da implantação dos pomares, após muitos anos de uma cultura perene (eucalipto). Entretanto, como houve destoca e subsolagem, essa contribuição pode ter sido restrita.

Segundo Harter \& Naidu (1995) e Aoyama (1996), outra explicação seria a formação de pares entre bases $\left(\mathrm{Ca}^{2+} \mathrm{e} \mathrm{Mg}^{2+}\right)$ e ácidos orgânicos ( $\mathrm{RO}^{-}$e $\left.\mathrm{RCOO}^{-}\right)$de alta solubilidade e baixa massa molecular, que permitiria o carreamento desses pares para camadas subsuperficiais. Essa reação é explicada por Miyazawa et al. (1996) pela formação de ligantes orgânicos, que complexam o Ca do solo, formando complexos $\mathrm{CaL}^{0}$ ou CaL: Além desses compostos, pode haver formação de outros, como $\mathrm{Ca}\left(\mathrm{HCO}_{3}\right)_{2}$ e $\mathrm{Mg}\left(\mathrm{HCO}_{3}\right)_{2}$, de acordo com Oliveira \& Pavan (1996), e, ainda, quando há adubação nitrogenada, pode ocorrer a formação de sais solúveis, como o nitrato de $\mathrm{Ca}$, que percolam pelo movimento descendente da água no perfil do solo (Blevins et al., 1997). É razoável supor, porém, que a soma das contribuições de todos os processos seja mais importante que cada um deles.

Independentemente do mecanismo envolvido, constata-se melhoria do ambiente químico do subsolo para as plantas. Essa descida do calcário no perfil do
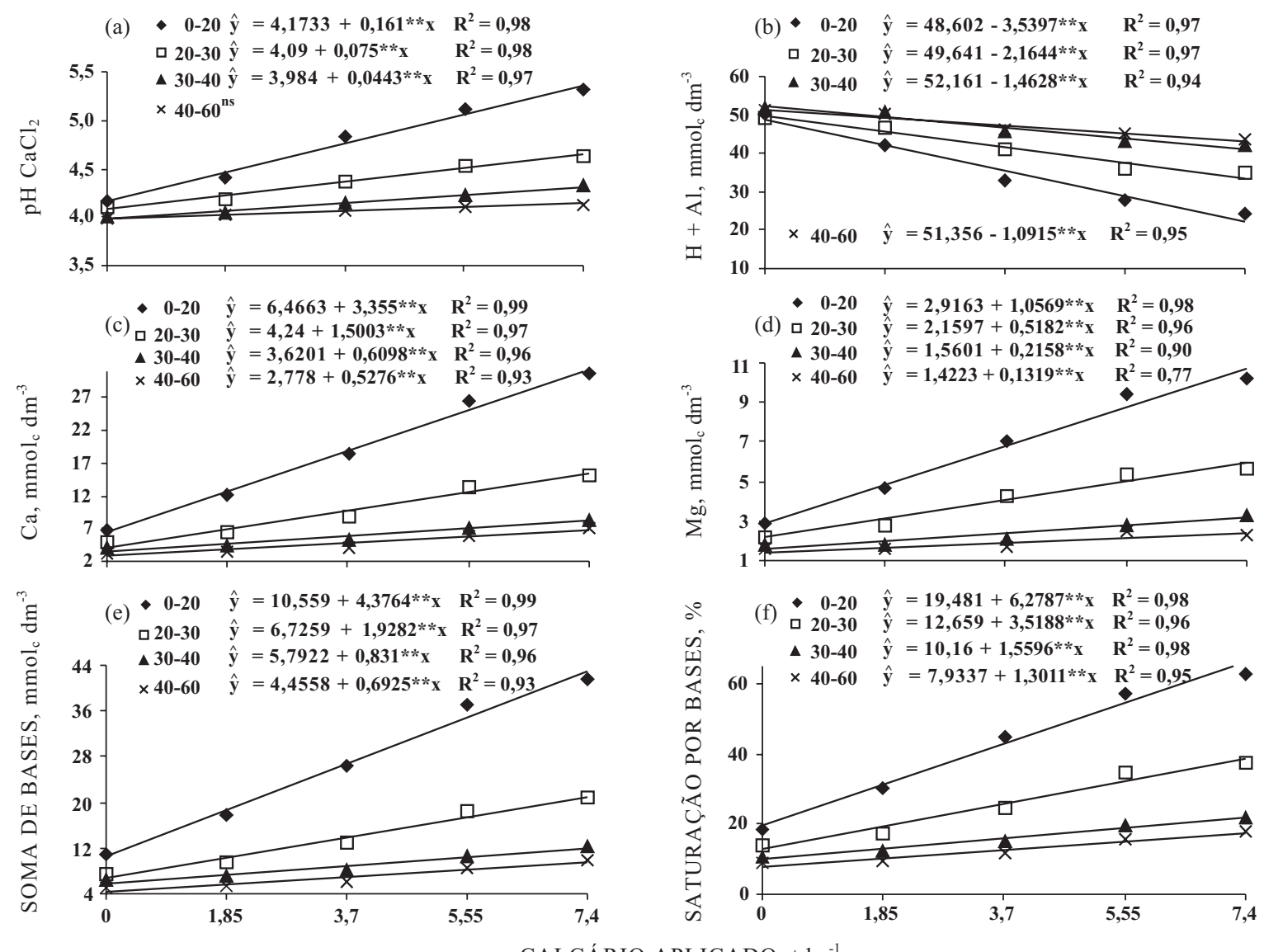

Figura 1. Efeito da aplicação de calcário no pH (a), H + Al (b), Ca (c), Mg (d), soma de bases (e) e saturação por bases (f), em diferentes profundidades do solo, em amostras da entrelinha da goiabeira. Os pontos são médias de 12, 10, 10 e nove épocas de amostragem, respectivamente, para as camadas de 0-20, 20-30, 30-40 e 40-60 cm e quatro repetições. ${ }^{* *}$ Significativo $p<0,01$ e * Significativo $p<0,05$. 
solo, com conseqüente correção da acidez abaixo da camada de incorporação, pode ter implicações práticas importantes, visto que a goiabeira possui sistema radicular profundo e abrangente (Moutounet et al., 1977; Bassoi et al., 2001).

Além disso, é importante destacar que, com a aplicação de calcário referente a duas vezes a dose indicada para elevar $\mathrm{V}$ a $70 \%$, foi obtido apenas $63 \%$ (Figura 1). Apesar de o método da necessidade de calcário, baseado na elevação da $\mathrm{V}$ do solo, apresentar fundamento adequado, têm sido freqüentemente relatados na literatura resultados em que os valores de $\mathrm{V}$, determinados após a calagem, foram inferiores aos estimados pelo método (Quaggio et al., 1982; Caires \& Rosolem, 1993; Oliveira et al., 1997). De acordo com Tescaro (1998), essa ineficiência em elevar a $\mathrm{V}$ a valores relativamente altos pode estar ligada ao potencial de cargas dependentes do $\mathrm{pH}$ do solo, normalmente alto, ao deslocamento da reação de equilíbrio da solubilização do corretivo e, ainda, à formação de novos minerais no solo, como hidróxidos pouco solúveis.
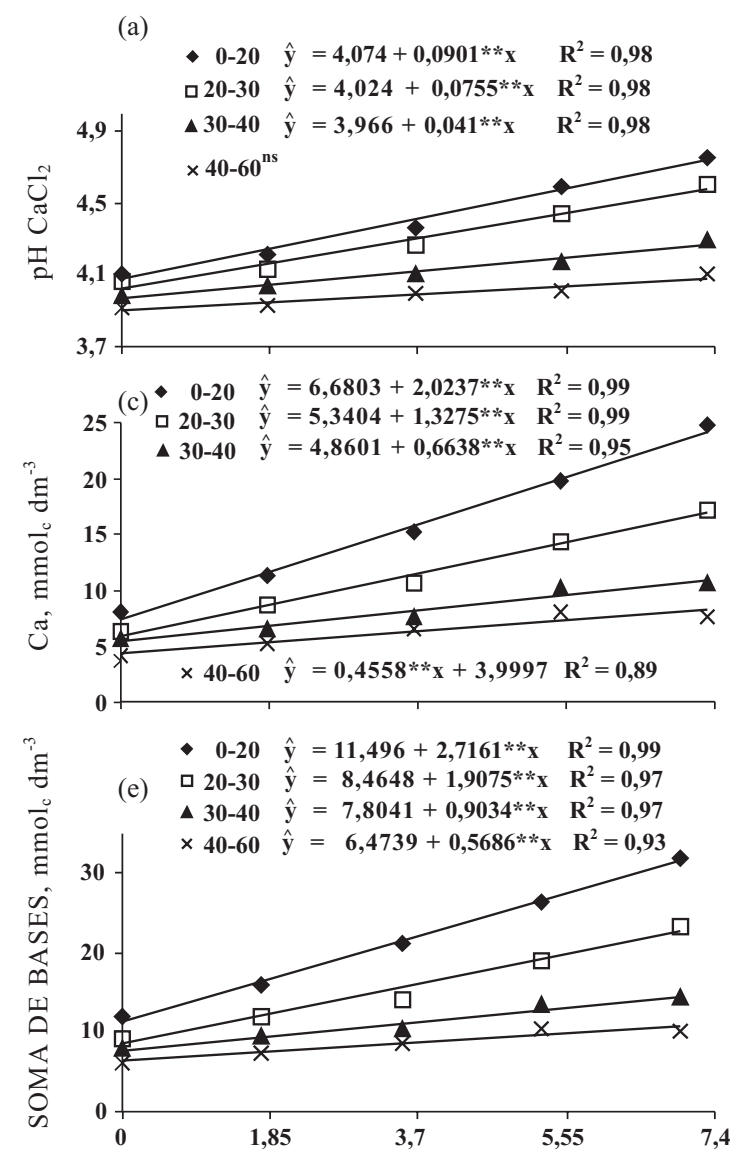

CALCÁRIO APLICADO, $\mathrm{t} \mathrm{ha}^{-1}$
Considerando que a $\mathrm{V}$ reflete, de maneira geral, os benefícios da calagem no solo (aumento do $\mathrm{pH}, \mathrm{Ca}^{2+}$, $\mathrm{Mg}^{2+}$ e SB e diminuição de $\mathrm{Al}^{3+}$ e do $\mathrm{H}+\mathrm{Al}$ ) e que, de forma resumida, pode representar tais modificações, optou-se por apresentar a V nas diferentes camadas analisadas, ao longo dos 78 meses de experimentação (Figura 3).

Avaliando os efeitos da aplicação do calcário dolomítico no decorrer do tempo (1999 a 2006), constata-se que houve reflexos positivos na $\mathrm{V}$ do solo já aos quatro meses após incorporação do corretivo, em amostras da entrelinha do pomar (Figura 3a). Na entrelinha (camada de 0-20 cm), apesar da flutuação dos valores de $\mathrm{V}$, houve estabilidade até cerca de 40 meses. A partir daí, teve início o decréscimo do efeito residual do calcário na entrelinha (Figura 3a) e, mais acentuadamente, na linha de plantio (Figura 3b), independentemente da camada analisada. Trabalhos de Quaggio et al. (1982) e Oliveira et al. (1997), em condições de campo, indicaram que a reação máxima do calcário no solo ocorreu entre 18 e 33 meses após a aplicação. Resultados da Embrapa (1981), porém,
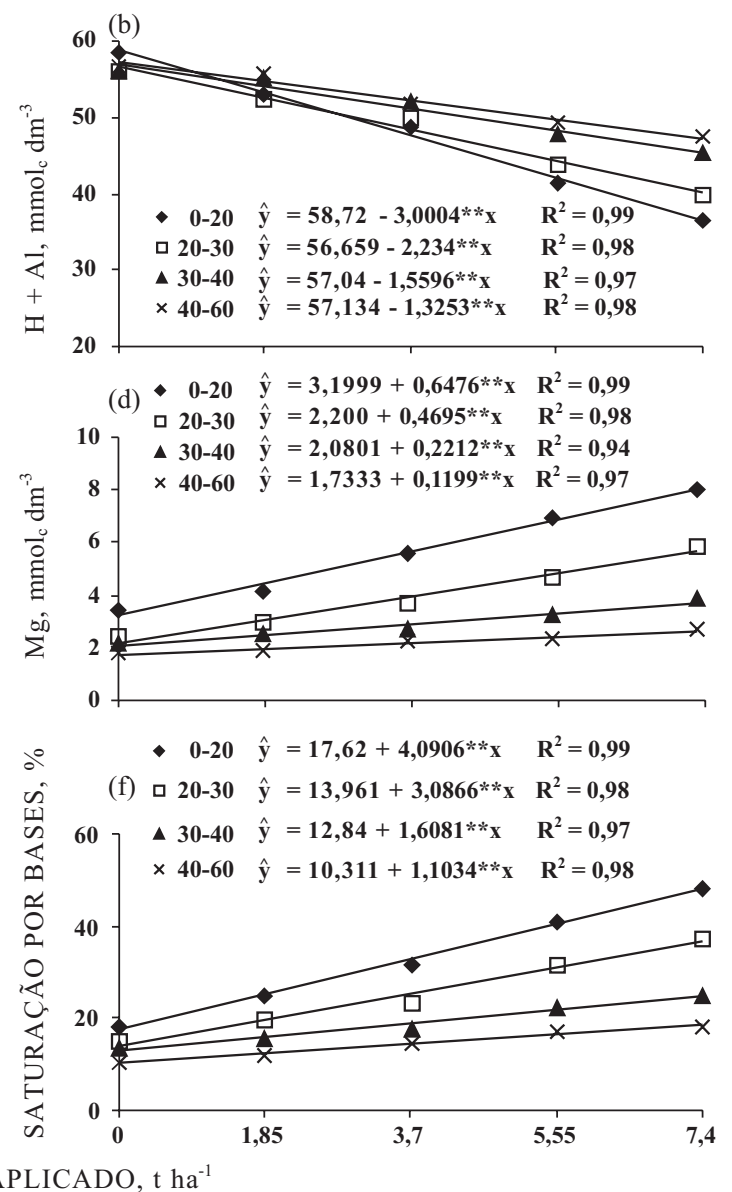

Figura 2. Efeito da aplicação de calcário no pH (a), H + Al (b), Ca (c), Mg (d), soma de bases (e) e saturação por bases (f), em diferentes profundidades do solo, em amostras da linha de plantio das goiabeiras. Os pontos são médias de 10 épocas de amostragem em cada uma das camadas de 0-20, 20-30 e 30-40 cm e nove épocas de amostragem na camada de $40-60 \mathrm{~cm}$, e quatro repetições. ${ }^{* *}$ Significativo p $<0,01$ e Significativo $\mathrm{p}<0,05$. 
indicaram que a reação máxima do calcário ocorreu aproximadamente quatro meses depois da aplicação. É importante ressaltar que as doses, tipos e PRNT dos calcários utilizados nos trabalhos citados diferem daqueles empregado no presente estudo. Outro aspecto que poderia estar influindo na velocidade de reação do calcário seriam os índices de reatividade adotados atualmente para o cálculo desta, que se apresentam superestimados dentro do prazo estipulado pela legislação brasileira, que é de até 90 dias. Natale \& Coutinho (1994) observaram que as reatividades das frações granulométricas atribuídas ao calcário pela legislação só foram obtidas cerca de 18 meses após a aplicação do corretivo ao solo.

Essas diferenças no tempo de reação do calcário devem-se a diversos fatores, entre os quais o podertampão do solo e o grau de homogeneização na incorporação do corretivo (Weirich Neto et al., 2000). Além disso, o regime hídrico do local pode afetar a velocidade de reação do calcário no solo ao longo do tempo.

Salienta-se que, na amostragem de solo da linha de plantio das goiabeiras, houve diminuição linear da V com o tempo decorrido (Figura 3b). Essa queda da $\mathrm{V}$, constatada por meio dos coeficientes de angulares das equações, foi maior nas camadas superficiais

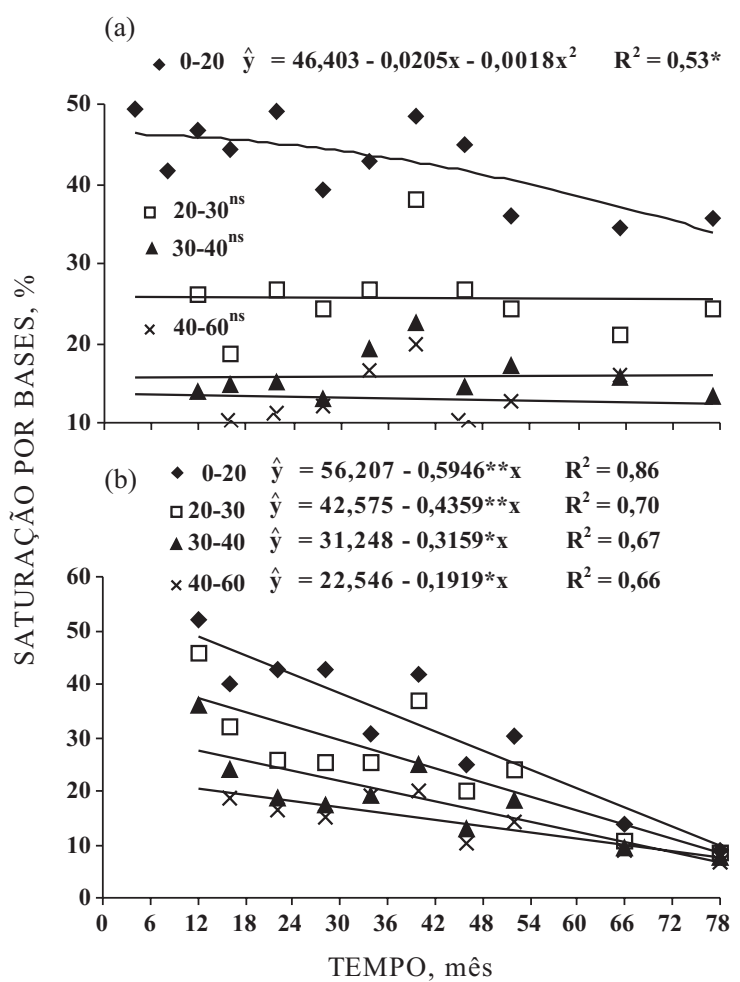

Figura 3. Efeito do tempo de aplicação do calcário na saturação por bases do solo cultivado com goiabeira, em amostras da entrelinha (a) e da linha (b) em diferentes profundidades de amostragem. Os pontos são médias de cinco doses de calcário e quatro repetições. Significativo $p<0,01 \mathrm{e}^{*}$ Significativo $\mathrm{p}<0,05$.
(0-30 cm), atingindo $0,6-0,4 \%$, comparada à camada subsuperficial $(30-60 \mathrm{~cm})$, que foi de $0,3-0,2 \%$. Isso se deve, provavelmente, ao maior efeito acidificante da adubação nitrogenada na camada superficial, bem como à irrigação. No presente experimento, houve diminuição anual de 5-7 \% da $V$ na camada superficial do solo, com o tempo de cultivo, na linha das goiabeiras.

\section{Efeito dos tratamentos na planta}

As análises químicas do tecido vegetal revelaram que houve efeito significativo da calagem nos teores foliares de $\mathrm{Ca}, \mathrm{Mg}, \mathrm{Mn}$ e $\mathrm{Zn}$. Os demais elementos, $\mathrm{N}, \mathrm{P}, \mathrm{Ke} \mathrm{S}$, bem como o B, Cu e Fe, avaliados durante todo o período experimental, não sofreram influência significativa das doses de corretivo, seja devido às adubações minerais regulares no pomar, seja devido ao esterco aplicado.

Os teores de macro e micronutrientes considerados adequados à goiabeira, de modo geral, situam-se para o N, P, K, Ca e Mg em 30, 3, 30, 13 e $3 \mathrm{~g} \mathrm{~kg}^{-1}$, e, para o Cu Fe, Mn e Zn, em 10-16, 144-162, 202-398 e 28$32 \mathrm{mg} \mathrm{kg}^{-1}$, respectivamente (Malavolta et al., 1997). Para a cultivar Paluma (a mesma empregada neste trabalho), Natale et al. (1996) indicam como adequadas as faixas de teores foliares de N, P, K, Ca, Mg e S de $20-23 ; 1,4-1,8 ; 14-17 ; 7-11 ; 3,4-4,0 ;$ e $2,5-3,5 \mathrm{~g} \mathrm{~kg}^{-1}$; e para $\mathrm{B}, \mathrm{Cu}, \mathrm{Fe}, \mathrm{Mn}$ e $\mathrm{Zn}$, de 20-25, 20-40, 60-90, 40-80, e 25-35 mg kg-1, respectivamente. Os teores de N, P, K e S mantiveram-se, ao longo dos anos, próximos aos limites inferiores das faixas consideradas adequadas para a frutífera por Natale et al. (1996).

Observaram-se efeitos lineares das doses de corretivo sobre os teores de $\mathrm{Ca}$ e $\mathrm{Mg}$ ao longo do experimento (exceção para o $\mathrm{Mg}$ em 2001), cujos coeficientes de determinação indicam o bom ajuste dos dados ao modelo linear (Figura 4). Esses incrementos nos teores foliares de $\mathrm{Ca}$ e $\mathrm{Mg}$ na goiabeira eram esperados, visto que o corretivo empregado foi o calcário dolomítico (Figuras 1 e 2).

Os teores foliares de Ca estiveram sempre na faixa considerada adequada por Natale et al. (1996), com exceção das goiabeiras do tratamento testemunha e as que receberam a menor dose de corretivo (Figura 4a). Contudo, os teores de $\mathrm{Mg}$ estiveram sempre abaixo daquele considerado adequado pelos autores anteriormente citados, independentemente do ano de avaliação ou da dose de corretivo empregada (Figura 4b).

Nos primeiros anos após implantação do pomar, verificou-se boa correlação entre os teores foliares de $\mathrm{Ca}$ e as concentrações do elemento no solo, tanto na entrelinha como na linha de plantio (Quadro 2). Entretanto, nos anos de 2004 e 2005, a correlação foi significativa apenas com as concentrações do elemento na entrelinha. De maneira geral, o mesmo ocorreu para o $\mathrm{Mg}$, observando-se relações mais estreitas do Mg nas folhas com aquele determinado na entrelinha do pomar. Isso pode indicar que, com o esgotamento 

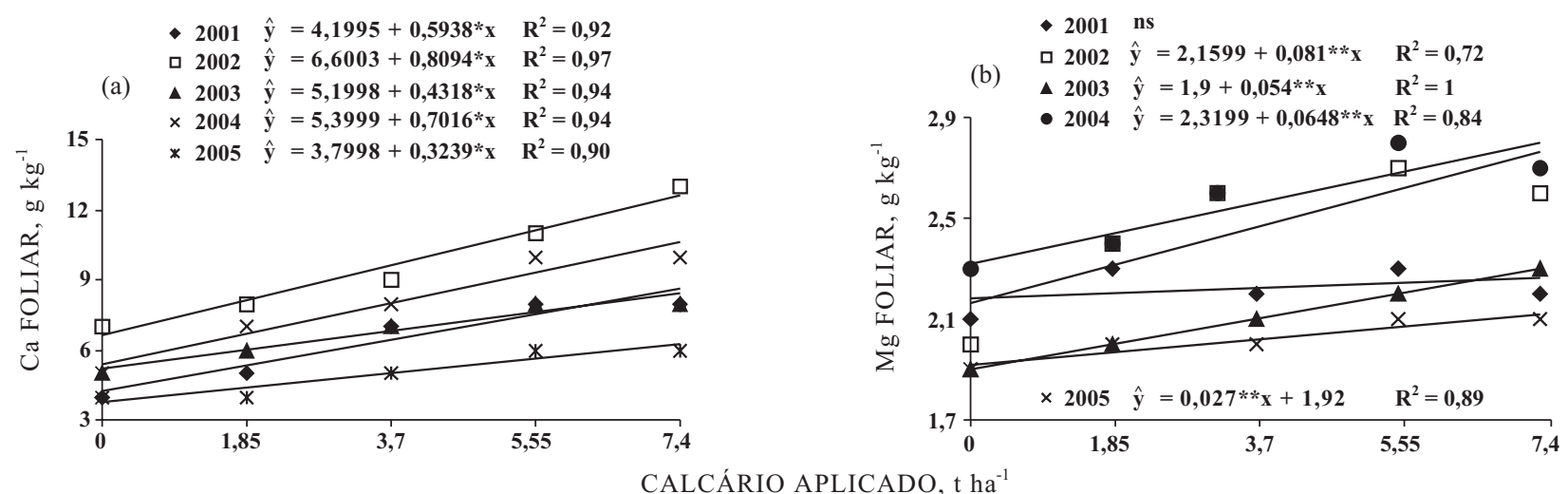

Figura 4. Efeito da aplicação de doses crescentes de calcário sobre os teores foliares de Ca (a) e Mg (b), no pomar de goiabeiras, avaliados em diferentes anos (dados médios de quatro repetições). ${ }^{* *}$ Significativo $\mathrm{p}<0,01$ e * Significativo $\mathrm{p}<0,05$.

Quadro 2. Coeficientes de correlação entre o teor de cálcio e de magnésio do solo na camada de 0-20 cm da entrelinha e linha do pomar e os teores foliares de Ca e Mg das goiabeiras, nos diferentes anos de cultivo (os valores são médias de quatro repetições em cada ano)

\begin{tabular}{|c|c|c|c|c|c|c|c|c|c|c|}
\hline \multirow{3}{*}{$\begin{array}{l}\text { Nutriente } \\
\text { no solo }\end{array}$} & \multicolumn{10}{|c|}{ Nutriente na folha } \\
\hline & \multicolumn{2}{|c|}{2001} & \multicolumn{2}{|c|}{2002} & \multicolumn{2}{|c|}{2003} & \multicolumn{2}{|c|}{2004} & \multicolumn{2}{|c|}{2005} \\
\hline & $\mathbf{C a}$ & $\mathrm{Mg}$ & $\mathbf{C a}$ & $\mathrm{Mg}$ & $\mathbf{C a}$ & Mg & $\mathbf{C a}$ & $\mathbf{M g}$ & $\mathbf{C a}$ & Mg \\
\hline $\mathrm{Ca}(\mathrm{L})$ & $0,91^{*}$ & & $0,99^{* *}$ & & $0,95^{*}$ & & $\mathrm{~ns}$ & & $\mathrm{~ns}$ & \\
\hline $\mathrm{Ca}(\mathrm{E})$ & $0,94^{*}$ & & $0,96^{* *}$ & & $0,99^{*}$ & & $0,97^{*}$ & & $0,93^{*}$ & \\
\hline $\mathrm{Mg}(\mathrm{L})$ & & ns & & $0,79^{*}$ & & $\mathrm{~ns}$ & & $\mathrm{~ns}$ & & $\mathrm{~ns}$ \\
\hline $\mathrm{Mg}(\mathrm{E})$ & & ns & & $0,92^{*}$ & & $0,97^{*}$ & & $0,81^{*}$ & & $0,84^{*}$ \\
\hline
\end{tabular}

E: entrelinha do pomar, L: linha de plantio das goiabeiras. ${ }^{* *},{ }^{*} e^{\text {ns }}$ Significativo $p<0,01, p<0,05$ e não-significativo, respectivamente.

dessas bases na linha de plantio, as raízes das goiabeiras absorveram os nutrientes de maneira mais efetiva na entrelinha da cultura. Em citros, Quaggio (1994) também verificou correlação significativa entre o Mg foliar e aquele na entrelinha do pomar.

Os teores foliares de Mn e Zn sofreram decréscimos significativos com o aumento das doses de calcário (Quadro 3). Apesar disso, permaneceram na faixa considerada adequada, ou acima desta, para a cultura indicada por Natale et al. (1996) e Malavolta et al. (1997), o que ocorreu, também, com os demais micronutrientes.

\section{Produção de frutos}

Verificou-se efeito significativo dos tratamentos sobre a produtividade, com exceção do ano de 2006, em que houve severo ataque de Puccinia psidii Wint, com queda generalizada dos frutos no pomar (Figura 5). E importante destacar o aumento de produtividade da safra de 2002 a 2005, que é resultado, após implantação do pomar, do crescimento da planta em altura, área foliar, etc. e, conseqüentemente, da capacidade produtiva. A melhoria do ambiente radicular das plantas devido à correção da acidez
Quadro 3. Efeito da aplicação de doses crescentes de calcário sobre os teores foliares de manganês e zinco em goiabeiras avaliadas em diferentes anos

\begin{tabular}{|c|c|c|c|}
\hline Ano & Nutriente & Equação & $\mathbf{R}^{2}$ \\
\hline \multirow[t]{2}{*}{2001} & $\mathrm{Mn}$ & $\hat{\mathrm{y}}=329,31-22,9353^{* *} \mathrm{x}$ & 0,80 \\
\hline & $\mathrm{Zn}$ & $\hat{y}=30,63-1,2035^{* *} x$ & 0,89 \\
\hline \multirow[t]{2}{*}{2002} & $\mathrm{Mn}$ & $\hat{\mathrm{y}}=26,33-1,7228^{* *} \mathrm{x}$ & 0,99 \\
\hline & $\mathrm{Zn}$ & $\hat{y}=26,81-0,9844^{* *} x$ & 0,92 \\
\hline \multirow[t]{2}{*}{2003} & $\mathrm{Mn}$ & $\hat{\mathrm{y}}=272,70-11,975^{* *} \mathrm{x}$ & 0,96 \\
\hline & $\mathrm{Zn}$ & $\hat{\mathrm{y}}=36,00^{\mathrm{ns}}$ & - \\
\hline \multirow[t]{2}{*}{2004} & $\mathrm{Mn}$ & $\hat{y}=-332,59-17,86^{* *} x$ & 0,91 \\
\hline & $\mathrm{Zn}$ & $\hat{\mathrm{y}}=37,00^{\mathrm{ns}}$ & - \\
\hline \multirow[t]{2}{*}{2005} & $\mathrm{Mn}$ & $\hat{\mathrm{y}}=209,06-13,33^{* *} \mathrm{x}$ & 0,94 \\
\hline & $\mathrm{Zn}$ & $\hat{\mathrm{y}}=27,96-0,8359^{* *} \mathrm{x}$ & 0,94 \\
\hline
\end{tabular}

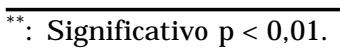

(Figuras 1a e 2a), bem como o fornecimento de Ca e Mg provenientes do calcário (Figuras 1c e 2c; $1 \mathrm{~d}$ e $2 \mathrm{~d}$ ), com conseqüente elevação dos teores foliares desses macronutrientes nas plantas (Figura 4), justificam, em parte, o incremento na produtividade de frutos (Figura 5). É importante destacar, ainda, que as 


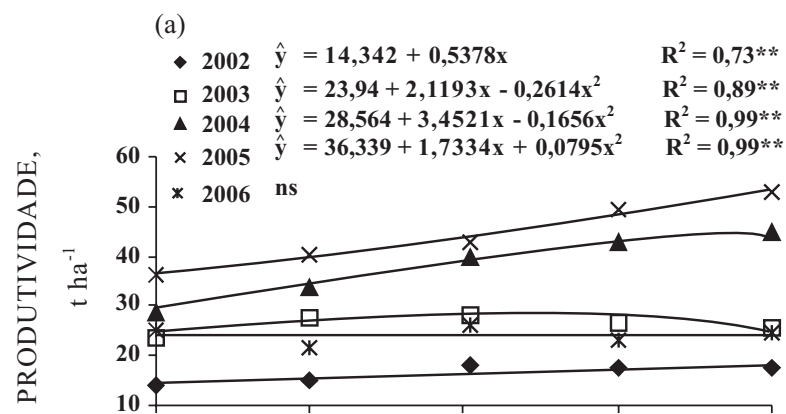

(b)

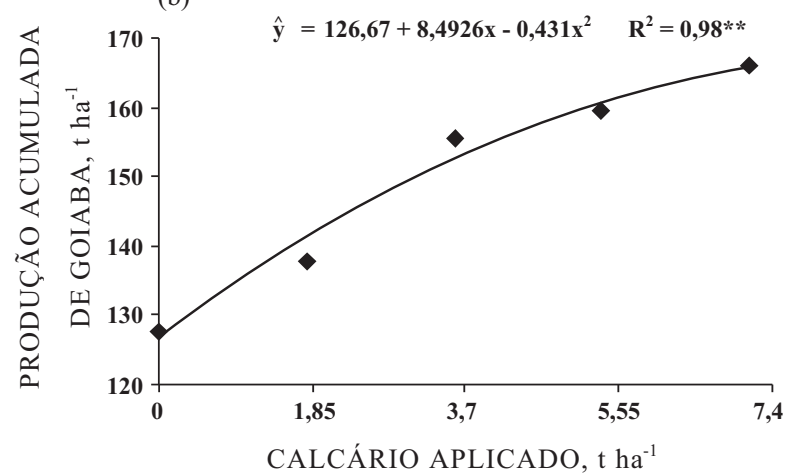

Figura 5. Efeito da aplicação de calcário dolomítico na produtividade de frutos de goiabeiras nas safras de 2002 a 2006 (a) e na produção acumulada de goiabas (b).

médias de produtividade das safras de 2002-2006 (Figura 5a) superam as médias de produtividade dos pomares comerciais adultos no Brasil - em 2003 a média foi de $18 \mathrm{t} \mathrm{ha}^{-1}$ de frutos (Agrianual, 2006). Isso se deve, especialmente, ao emprego de cultivar mais produtiva, que exige, porém, manejo da calagem, da adubação e do uso de irrigação mais adequadas.

A produção acumulada de frutos no período experimental (2002 a 2006) está apresentada na figura 5b. Observa-se o bom ajuste dos dados de produção acumulada ao modelo quadrático, em função das doses de corretivo.

Quanto à dependência entre os teores foliares de Ca e Mg nas goiabeiras e a produção acumulada de frutos, observou-se efeito quadrático para o $\mathrm{Ca}$ (Figura 6a) e para o $\mathrm{Mg}$ (Figura 6b). A relação $\mathrm{Ca} /$ Mg mostra, por outro lado, que valores muito estreitos dessa relação são prejudiciais à produção acumulada de goiabas (Figura 7). O conhecido efeito de competição entre bases no solo (Ca e Mg), com reflexos na absorção e nos teores foliares dos nutrientes (Moore et al., 1961), justifica o comportamento da planta, em relação à produção.

Observou-se incremento, com ajuste quadrático, na produção acumulada de frutos (safras de 20022006), em função da saturação por bases na camada superficial do solo, na entrelinha e na linha das goiabeiras (Figura 8). Apesar de os pontos de máxima produção estarem além dos valores constatados no

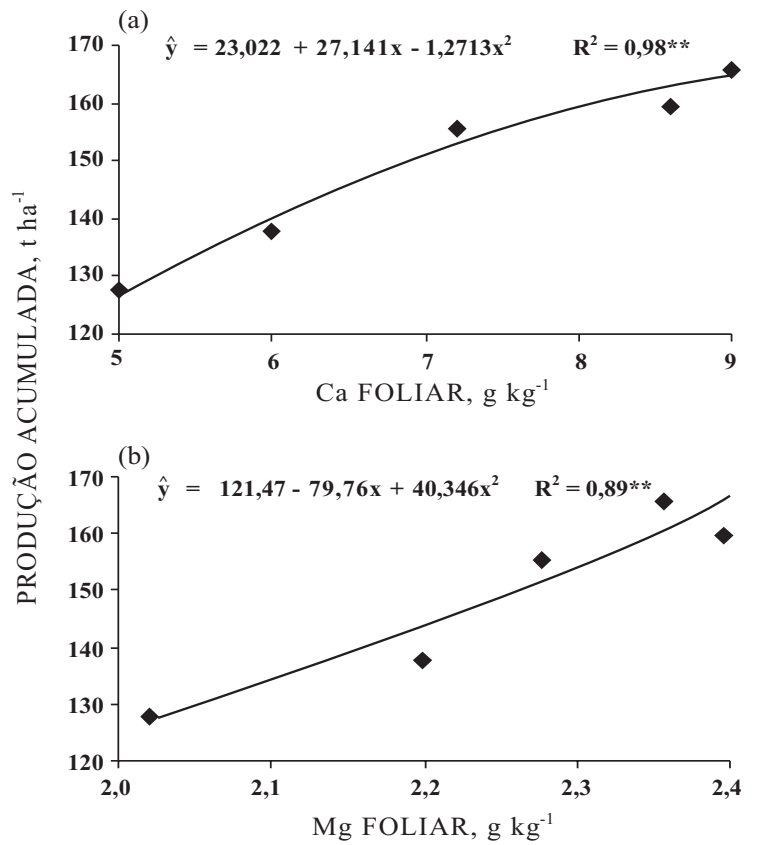

Figura 6. Relação entre os teores foliares de cálcio (a) e magnésio (b) e produção acumulada de frutos de goiabeiras nas safras de 2002 a 2006. Os pontos são médias de quatro repetições em cada ano.

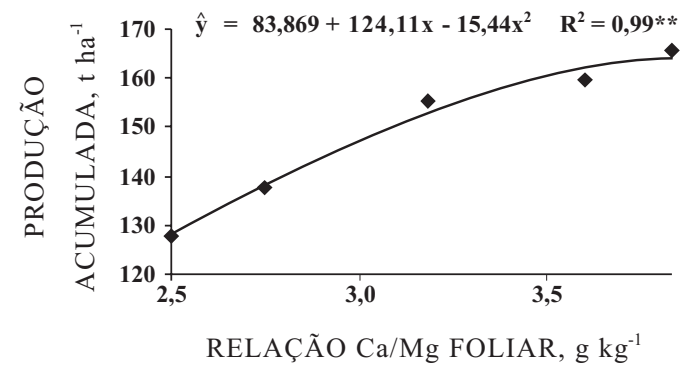

Figura 7. Relação entre $\mathrm{Ca} / \mathrm{Mg}$ foliar e produção acumulada de frutos das goiabeiras nas safras de 2002 a 2006 . Os pontos são médias de quatro repetições em cada ano.

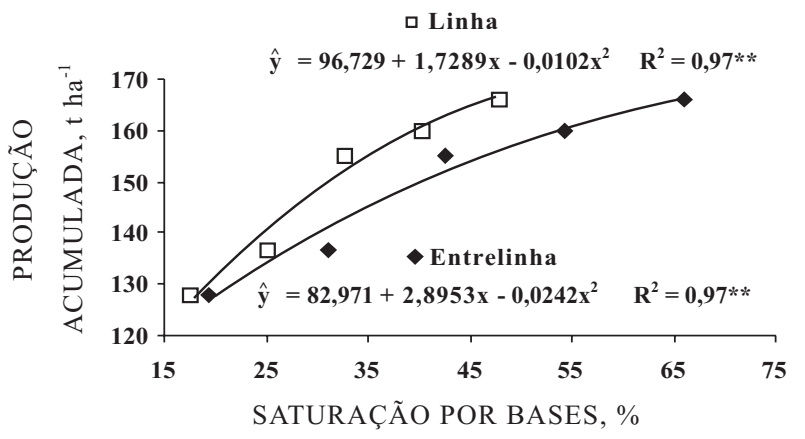

Figura 8. Relação entre a saturação por bases do solo, na camada de 0-20 cm, na entrelinha e na linha do pomar de goiabeiras (média de todas as amostragens) e a produção acumulada de frutos nos anos agrícolas de 2002 a 2006. 
experimento, pode-se inferir que maiores valores de produção acumulada de frutos são obtidos quando $\mathrm{V}$ estiver próximo de $50 \%$ na linha da cultura e de $65 \%$ na entrelinha do pomar. Santos \& Quaggio (1996) indicaram para a goiabeira no Estado de São Paulo valor de $\mathrm{V}=70 \%$, não informando, porém, se a $\mathrm{V}$ é para a implantação do pomar ou para a fase produtiva.

\section{CONCLUSÕES}

1. A calagem promove melhoria dos atributos químicos do solo ligados à acidez, elevando o $\mathrm{pH}, \mathrm{Ca}^{2+}$, $\mathrm{Mg}^{2+}, \mathrm{SB}$ e $\mathrm{V}$ e diminuindo o $\mathrm{H}+\mathrm{Al}$, até $60 \mathrm{~cm}$ de profundidade, tanto na entrelinha como na linha da cultura.

2. A calagem eleva os teores foliares de Ca e Mg, os quais se correlacionaram positivamente com a produção de frutos das goiabeiras.

3. A maior produção acumulada de frutos esteve associada à saturação por bases no solo próxima a $50 \%$ na linha e $65 \%$ na entrelinha do pomar.

\section{LITERATURA CITADA}

AGRIANUAL. Anuário da agricultura brasileira. São Paulo, FNP Consultoria e Comércio, 2006. p.332.

AOYAMA, M. Fractionation of water-soluble organic substances formed during plant residue decomposition and high performance size exclusion chromatography of the fractions. Soil Sci. Plant Nutr., 42:21-30, 1996.

BARBER, S.A. Liming materials and pratices. In: PEARSON, R.W. \& ADAMS, F., eds. Soil acidity and liming. Madison, American Society of Agronomy, 1967. p.125-160.

BASSOI, L.H.; SILVA, J.A.M.; SILVA, E.E.G.; FERREIRA, M.N.L.; MAIA, J.L.T. \& TARGINO, E.L. Informações sobre a distribuição das raízes da goiabeira para o manejo da irrigação. Petrolina, Embrapa Semi-Árido, 2001. 4p. (Comunicado Técnico, 111)

BATAGLIA, O.C.; FURLANI, A.M.C.; TEIXEIRA, J.P.F.; FURLANI, P.R. \& GALLO, J.R. Métodos de análise química de plantas. Campinas, Instituto Agronômico, 1983. 48p. (Boletim Técnico, 78)

BERNARDO, S. Manual de irrigação. 6.ed. Viçosa, MG, Universidade Federal de Viçosa, 2002. 656p.

BLEVINS, R.L.; THOMAS, G.W. \& CORNELUIS, P.L. Influence of no-tillage and nitrogen fertilization on certain soil properties after 5 years of continuous corn. Agron. J., 69:383-386, 1977.

CAIRES, E.F. \& ROSOLEM, C.A. Calagem em genótipos de amendoim. R. Bras. Ci. Solo, 17:193-202, 1993.
DEMATTÊ, J.L.I. \& VITTI, G.C. Alguns aspectos relacionados ao manejo de solos para citros. In: SIMPÓSIO INTERNACIONAL DE CITROS. FISIOLOGIA, 2, Bebedouro, 1992. Anais. Bebedouro, Fundação Cargill, 1992. p.67-99.

EMBRAPA. EMPRESA BRASILEIRA DE PESQUISA AGROPECUÁRIA - EMBRAPA. Centro de Pesquisa Agropecuária dos Cerrados. Relatório Técnico Anual. Planaltina, 1981 190p.

EMBRAPA. EMPRESA BRASILEIRA DE PESQUISA AGROPECUÁRIA - EMBRAPA. Centro Nacional de Pesquisa de Solo. Sistema brasileiro de classificação de solos. Brasília, Produção de Informações, 1999. 412p.

ENGELS, C. \& MARSCHNER, H. Plant uptake and utilization of nitrogen. In: BACON, P.E., ed. Nitrogen fertilization in the environment. New York, M. Dekker, 1995. p.4181.

GONZALES-ÉRICO, E.; KAMPRATH, E.J.; NADERMANN, G.C. \& SOARES, W.V. Effect of depth of lime incorporation on the growth of corn on an Oxisol of Central Brazil. Soil Sci. Soc. Am. J., 43:1155-1158, 1979.

HARTER, R.D. \& NAIDU, R. Role of metal-organic complexation in metal sorption by soils. Adv. Agron., 55:219-263, 1995.

LIBARDI, P.L. \& REICHARDT, K. Destino da uréia aplicada a um solo tropical. R. Bras. Ci. Solo, 2:40-44, 1978.

MALAVOLTA, E. Manual de nutrição mineral de plantas. Piracicaba, Ceres, 2006. 638p.

MALAVOLTA, E.; VITTI, G.C. \& OLIVEIRA, S.A. Avaliação do estado nutricional das plantas: Princípios e aplicações. 2 ed. Piracicaba, Potafos, 1997. 319p.

MIYAZAWA, M.; PAVAN, M.A. \& SANTOS, J.C.F. Effects of addition of crop residues on the leaching of $\mathrm{Ca}$ and $\mathrm{Mg}$ in Oxisols. In: INTERNATIONAL SYMPOSIUM ON PLANT-SOIL INTERACTIONS AT LOW $\mathrm{pH}, 4$. , Belo Horizonte, 1996. Abstracts. Belo Horizonte, SBCS/ Embrapa-CPAC,1996. p.8.

MOORE, D.P.; OVERSTREET, R. \& JACOBSON, L. Uptake of magnesium and its interactions with calcium in excised barley roots. Plant Physiol., 36:290-295, 1961.

MOUTOUNET, B.; AUBERT, B.; GOUSSELAND, J.; TIAWCHAN, P.; PAYET, O. \& JOSON, J. Étude de l'enracinement de quelques arbres frutiers sur sol ferrallitique brun profound. Fruits, 32:321-333, 1977.

NATALE, W. Diagnose da nutrição nitrogenada e potássica em duas cultivares de goiabeira (Psidium guajava L.), durante três anos. Piracicaba, Escola Superior de Agricultura Luiz de Queiroz, 1993. 150p. (Tese de Doutorado)

NATALE, W. Resposta da goiabeira à adubação fosfatada. Jaboticabal, Universidade Estadual de São Paulo, 1999. 132p. (Tese de Livre-Docência) 
NATALE, W. \& COUTINHO, E.L.M. Avaliação da eficiência agronômica de frações granulométricas de um calcário dolomítico. R. Bras. Ci. Solo, 18:55-62, 1994.

NATALE, W.; COUTINHO, E.L.M.; BOARETTO, A.E. \& PEREIRA, F.M. Goiabeira: Calagem e adubação. Jaboticabal, Funep, 1996. 22p.

OLIVEIRA, E.L. \& PAVAN, M.A. Control of soil acidity in notillage system for soybean production. Soil Till. Res., 38:47$57,1996$.

OLIVEIRA, E.L.; PARRA, M.S. \& COSTA, A. Resposta da cultura do milho, em um Latossolo Vermelho álico, à calagem. R. Bras. Ci. Solo, 21:65-70, 1997.

PEARSON, R.W.; ABRUNA, F. \& VICE-CHANCES, J. Effect of lime and nitrogen applications on downward movements of calcium and magnesium in two humid soils of Puerto Rico. Soil Sci., 93:77-82, 1962.

PIMENTEL-GOMES, F. Curso de estatística experimental. São Paulo, Nobel, 1985. 466p.

PIZA JÚNIOR, C.T. A poda da goiabeira de mesa. Campinas, CATI, 1994. 30p. (Boletim Técnico, 222)

PIZA JÚNIOR, C.T. \& KAVATI, R. A cultura da goiaba de mesa. Campinas, CATI, 1994. 28p. (Boletim Técnico, 219)

PRADO, R.M. Efeito da calagem no desenvolvimento, no estado nutricional e na produção de frutos da goiabeira e da caramboleira. Jaboticabal, Universidade Estadual Paulista, 2003. 68p. (Tese de Doutorado)

QUAGGIO, J.A. Acidez e calagem em solos tropicais. Campinas, Instituto Agronômico, 2000. 111p.

QUAGGIO, J.A. Métodos de aplicação do calcário em culturas anuais e perenes. In: SIMPÓSIO SOBRE APLICAÇÃO DE CALCÁRIO NA AGRICULTURA, Campinas, 1986. Anais. Campinas, Fundação Cargill, 1986. p.21.
QUAGGIO, J.A. Variações na interpretação de resultados de análise de solo, em função do local de amostragem, na citricultura. In: REUNIÃO BRASILEIRA DE FERTILIDADE DO SOLO E NUTRIÇÃO DE PLANTAS, 21., Petrolina, 1994. Anais. Petrolina, SBCS/Embrapa, 1994. p.405-407.

QUAGGIO, J.A.; DECHEN, A.R. \& RAIJ, B. van. Efeitos da aplicação de calcário e gesso sobre a produção de amendoim e lixiviação de bases no solo. R. Bras. Ci. Solo, 6:189-194, 1982.

RAIJ, B.van; ANDRADE, J.C.; CANTARELLA, H. \& QUAGGIO, J.A., eds. Análise química para a avaliação da fertilidade de solos tropicais. Campinas, Instituto Agronômico, 2001. 285p.

REY, J.Y. Etude architecturale de la partie aérienne du goyavier. Montpellier, Université de Montpellier II, 1987.49p. (Tese de Doutorado)

SANCHEZ, P.A. \& SALINAS, J.G. Suelos acidos: Estrategias para su manejo con bajos insumos en America Tropical. Bogotá, La Sociedad Colombiana de la Ciencia del Suelo, 1983. 93p.

SANTOS, R.R. \& QUAGGIO, J.A. Goiaba. In: RAIJ, B. van.; CANTARELLA, H.; QUAGGIO, J.A. \& FURLANI, A.M.C. Recomendações de adubação e calagem para o Estado de São Paulo. Campinas, Instituto Agronômico, 1996. p.143. (Boletim Técnico, 100)

SAS INSTITUTE. SAS User's guide: Statistics. 5.ed. Cary, 1985. $956 \mathrm{p}$.

TESCARO, M.D. Eficiência do método da saturação de bases para a correção da acidez de um solo Álico. In: REUNIÃO BRASILEIRA DE FERTILIDADE DO SOLO E NUTRIÇÃO DE PLANTAS, 23., Caxambu, 1998. Resumos. Caxambu, UFLA/SBCS/SBM, 1998. p.103.

WEIRICH NETO, P.H.; CAIRES, E.F.; JUSTINO, A. \& DIAS, J. Correção da acidez do solo em função de modos de incorporação de calcário. Ci. Rural, 30:257-261, 2000. 